\title{
Rescued expression of WIF-1 in gallbladder cancer inhibits tumor growth and induces tumor cell apoptosis with altered expression of proteins
}

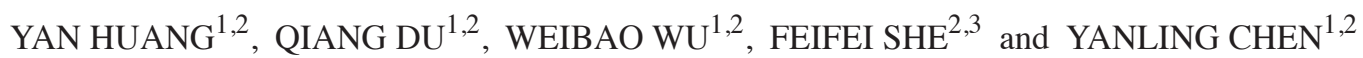 \\ ${ }^{1}$ Department of Hepatobiliary Surgery, The Affiliated Union Hospital of Fujian Medical University; \\ ${ }^{2}$ Key Laboratory of Ministry of Education for Gastrointestinal Cancer; ${ }^{3}$ Key Laboratory of Tumor Microbiology, \\ School of Basic Medical Sciences, Fujian Medical University, Fuzhou, Fujian 350001, P.R. China
}

Received July 20, 2015; Accepted June 24, 2016

DOI: $10.3892 / \mathrm{mmr} .2016 .5532$

\begin{abstract}
As a highly conserved metabolic pathway, the Wnt signaling pathway is involved in cell differentiation, proliferation and several other processes. In normal cells, this pathway is suppressed, and abnormal activation is often associated with tumor occurrence and development. In certain types of tumor, Wnt inhibitory factor 1 (WIF-1), an inhibitor of the Wnt pathway, inhibits tumor growth. However, the effect of the expression of WIF-1 on gallbladder cancer remains to be fully elucidated. In the current study, reverse transcription-quantitative polymerase chain reaction and western blotting were conducted. The present study demonstrated that, in gallbladder cancer, WIF-1 generally exhibited low levels of expression as a result of gene promoter methylation. Treatment with the drug, 5-aza-2-deoxycytidine, increased the expression of WIF-1 in the GBC-SD gallbladder cell line. In addition, a WIF-1-expression plasmid was transfected into GBC-SD cells, and it was found that cell proliferation, invasion and metastasis declined significantly, whereas the apoptotic rate increased. A nude mouse tumor transplantation experiment showed that the oncogenicity of the GBC-SD cells expressing WIF-1 was substantially lower, compared with that of the untransfected GBC-SD cells and of GBD-SD cells expressing the control plasmid. A fluorescent protein chip experiment showed that the restored expression of WIF-1
\end{abstract}

Correspondence to: Dr Yanling Chen, Department of Hepatobiliary Surgery, The Affiliated Union Hospital of Fujian Medical University, 29 Xinquan Road, Fuzhou, Fujian 350001, P.R. China

E-mail: drchenyl@126.com

Professor Feifei She, Key Laboratory of Tumor Microbiology, School of Basic Medical Sciences, Fujian Medical University, 29 Xinquan Road, Fuzhou, Fujian 350001, P.R. China

E-mail: shefeifei@yeah.net

Key words: Wnt inhibitory factor 1, Wnt, immunohistochemistry, gallbladder carcinoma, GBC-SD affected the expression of several cellular proteins. These alterations may explain the different biological behavior of the tumor cells expressing WIF-1. As an effective inhibitory factor of the Wnt signaling pathway, WIF-1 modulated the expression of proteins controlling the proliferation, apoptosis and metastasis of gallbladder tumor cells, thus suppressing the tumor. Therefore, WIF-1 may be an effective treatment target for gallbladder cancer.

\section{Introduction}

In China, gallbladder carcinoma is the fifth most common type of cancer of the digestive system (1) and is the most frequent type of cancer of the biliary system. Early diagnosis and early treatment are required to cure gallbladder cancer, however, the majority of patients do not receive medical assistance in time to receive surgical treatment $(2,3)$. The poor rates of prognosis are predominantly due to the rapid development of the tumor and invasion of the surrounding organs. Thus, a therapeutic strategy aimed at controlling the invasion and metastasis of gallbladder cancer is necessary.

In 1982, Nusse and Varmus (4) first identified the Wnt gene in mice, which was termed Int-1. Since then, several members of the Wnt gene family have been identified. The Wnt gene family is involved in a series of complex metabolic pathways and is involved in embryonic development, cell proliferation, migration, differentiation and other activities (5). In normal cells, the Wnt pathway is suppressed, and abnormal activation is associated with several types of malignant tumor (6-9). In 1999, Hsieh et al (10), reported a novel extracellular inhibitor protein, which can bind to Wnt proteins and affect their function. This was termed Wnt inhibitory factor 1 (WIF-1). At present, the gene sequence for WIF-1 has been determined, and its spatial structure has also been confirmed (11). WIF-1 belongs to the secreted Frizzled-related protein family and can inhibit the classical and non-classical Wnt signaling pathways $(12,13)$. The abnormal expression of WIF-1 in certain types of tumor has also been confirmed (14-16). However, the expression of WIF-1 in gallbladder cancer, the effects of WIF-1 on the biological behavior of gallbladder cancer and the associated mechanisms remain to be fully elucidated 
In the present study, it was shown in gallbladder tumors and three gallbladder cancer cell lines that the expression levels of WIF-1 were low. This low expression was associated with methylation of the WIF-1 gene promoter. Following treatment of GBC-SD cells with 5-aza-2-deoxycytidine (5-Aza-dC), the expression of WIF-1 recovered. The current study aimed to elucidate the effects of WIF-1 on tumor growth, invasion and metastasis, thus a GBC-SD cell line was constructed, which stably expressed WIF-1, and the expression of proteins closely associated with the Wnt signaling pathway were analyzed. It was found that WIF-1 significantly inhibited tumor cell proliferation, migration and invasion, and increased the apoptotic rate of the tumor cells. Protein expression levels were also altered following transfection. These results showed that WIF-1 markedly inhibited tumor growth, invasion and metastasis. Therefore, WIF-1 may be an effective treatment target for gallbladder cancer.

\section{Materials and methods}

Case collection and immunohistochemistry. A total of 40 gallbladder cancer specimens were collected from the Union Hospital of Fujian Medical University (Fujian, China), following surgical resection between 2004 and 2011. Of the 40 patients, 18 were male and 22 were female, 19 patients were $>60$ years old and 21 were $<60$ years old. All cases were confirmed by histopathological examinations. In addition, 50 chronic cholecystitis specimens were collected from the Union Hospital of Fujian Medical University following surgical resection in 2012, and were confirmed by histopathological examinations. Of the 50 patients, 28 were male and 22 were female and the ages ranged between 42 and 65 . The current study was approved by the ethics committee of the Affiliated Union Hospital of Fujian Medical University (Fuzhou, China). The rabbit anti-human monoclonal WIF-1 antibody (\#5502; 1:200; incubation at $4^{\circ} \mathrm{C}$ for $8 \mathrm{~h}$ ) was purchased from Cell Signaling Technology, Inc. (Danvers, MA, USA) and a goat anti-rabbit secondary antibody kit (kt-9903; 1:50; incubation at $37^{\circ} \mathrm{C}$ for $20 \mathrm{~min}$ ) was purchased from Beijing ZhongShan Biotechnology Company (Beijing, China). The expression of WIF-1 was detected using routine En Vision two-step immunohistochemical staining (Fuzhou Maxim Biotech, Inc., Fuzhou, China). Selected paraffin blocks $\left(4 \mu \mathrm{m}\right.$ thick) were heated $\left(92-98^{\circ} \mathrm{C}\right)$ for antigen retrieval in an alkaline environment following sectioning, heating, dewaxing and hydration. Subsequently, hydrogen peroxide was added and incubated at room temperature for $10 \mathrm{~min}$ to block endogenous peroxidase activity. Primary antibody incubation was performed at room temperature at a dilution of 1:100. Secondary antibody incubation was then performed, according to the instructions provided with the secondary antibody kit. The final step involved diaminobenzidine staining. The sections were then subjected to a gradient of ethanol dehydration, cleared in xylene and fixed with neutral balata. The expression of WIF-1 was predominantly located in the cytoplasm. Staining, which was located only in the membrane and nucleolus was considered negative using a BX51 microscope (Olympus Corporation, Tokyo, Japan).

Cell lines, reverse transcription-polymerase chain reaction (RT-PCR) and western blot analyses. The GBC-SD gallbladder cancer cell line was purchased from the Shanghai Institute of Cellular Biology of the Chinese Academy of Sciences (Shanghai, China). The SGC-996 cell line was purchased from the Life Science and Technology Institute of Tongji University (Shanghai, China). The NOZ cell line was obtained from the Japanese Health Science Research Resources Bank (Osaka, Japan). The cells were cultured in Dulbecco's modified Eagle's medium (DMEM; Gibco; Thermo Fisher Scientific, Inc., Waltham, MA, USA) with $10 \%$ fetal bovine serum (Gibco; Thermo Fisher Scientific, Inc.).

A First-Strand cDNA Synthesis kit was purchased from Fermentas; Thermo Fisher Scientific, Inc. The primers for WIF-1 and $\beta$-actin were designed using Oligo- 6 software. The upstream primer for WIF-1 was 5'-ATCATCTTCTTAACT GGCATTGTG-3' and the downstream primer was 5'-GCT GTAGAGGTTGACTGTGTAG-3'; the product was $328 \mathrm{bp}$. The upstream primer for WIF-1 was $\beta$-actin 5'-GGCATGGGT CAGAAGGATTCC-3' and the downstream primer was 5'-ATG TCACDCACGATTTCCCGC-3'; the product was $250 \mathrm{bp}$. RNA was extracted using TRIzol (Invitrogen; Thermo Fisher Scientific, Inc.) from the three tumor cell lines in the logarithmic growth phase, and the following steps were performed, as described in the kit instructions. The reaction volume for WIF- 1 and $\beta$-actin was $25 \mu \mathrm{l}$, including $3 \mu \mathrm{l}$ of template DNA, $1 \mu \mathrm{l}$ of the upstream primer and $1 \mu \mathrm{l}$ of the downstrean primer and $12.5 \mu \mathrm{l}$ of Taq PCR Mastermix (Bioteke Corp., Beijing, China); diethyl pyrocarbonate (DEPC) water was added to a final volume of $25 \mu \mathrm{l}$. The reaction conditions were as follows: Hot start at $94^{\circ} \mathrm{C}$ for $2 \mathrm{~min} ; 30$ cycles of $30 \mathrm{sec}$ at $94^{\circ} \mathrm{C}, 30 \mathrm{sec}$ at $57^{\circ} \mathrm{C}$ and $60 \mathrm{sec}$ at $72^{\circ} \mathrm{C}$, with a final extension step for $10 \mathrm{~min}$ at $72^{\circ} \mathrm{C}$. The results were assessed using a UV gel imaging system (JS-2010; Shanghai Peiqing Science and Technology Co., Ltd., Shanghai, China).

When the cells reached $80 \%$ confluency, they were washed twice with phosphate-buffered saline, following which $300 \mu \mathrm{l}$ of radioimmunoprecipitation assay lysis buffer containing $1 \%$ phenylmethanesulfonyl fluoride was added, and the cells were then removed using a cell scraper. The samples were transferred into tubes and lysed on ice for $30 \mathrm{~min}$. The following steps were performed, according to a standard western blotting protocol. The proteins extracted from the cells $(20 \mu \mathrm{l} ; 2 \mu \mathrm{g} / \mu \mathrm{l})$ were separated using $10 \%$ sodium dodecyl sulfate-polyacrylamide gel electrophoresis (Beyotime Institute of Biotechnology, Beijing, China), and electrophoretically transferred onto polyvinylidene fluoride membranes. The membranes were then incubated with antibodies against WIF-1, $\beta$-catenin and $\beta$-actin. Proteins were revealed by secondary antibody incubation. The final blots were scanned on an imaging system (JS-2010; Shanghai Peiqing Science and Technology Co., Ltd.) in order to quantify them, and the ratio between $\beta$-actin and WIF-1 was calculated to show the different expression.

WIF-1 gene promoter methylation in the GBC-SD gallbladder carcinoma cell line. The upstream primer for the methylated WIF-1 gene promoter was 5'-AATTTTATTGGTTGAAAG GGAGAC-3' and the downstream primer was 5'-AAAAAT AAAAAAAACACGCT-3'. These primers were designed using Oligo 6 software (Molecular Biology Insights, Inc. Cascade, CO, USA). The product size was $167 \mathrm{bp}$. The unmethylated upstream primer was 5'-GAATTTTATTGGTTGAAA GGGAGAT-3' and the downstream was 5'-AAAAATAAA 
AAAAACAAACAACACT-3'; the product size was 168 bp. Commercial kits are available to replace the technology of early standard bisulfite treatment (17). A cell/tissue genomic DNA extraction kit (centrifugal column type) and EZ DNA Methylation-GoldTM kit were purchased from Zymo Research (Irvine, CA, USA), and used according to the manufacturer's recommended protocol. The reaction was performed with a sample volume of $25 \mu \mathrm{l}$, comprising $1.5 \mu \mathrm{l}$ of template DNA, $0.5 \mu \mathrm{l}$ of either upstream or downstream primer, $12.5 \mu \mathrm{l}$ of Taq PCR Mastermix (Bioteke Corp.) and DEPC water to $25 \mu \mathrm{l}$. The reaction included a hot start at $95^{\circ} \mathrm{C}$ for $10 \mathrm{~min}$, and the amplifications were performed in a thermal cycler for 40 cycles of $45 \mathrm{sec}$ at $95^{\circ} \mathrm{C}, 45 \mathrm{sec}$ at $57^{\circ} \mathrm{C}, 45 \mathrm{sec}$ at $72^{\circ} \mathrm{C}$ and a final extension step for $10 \mathrm{~min}$ at $72^{\circ} \mathrm{C}$.

The present study used 5-Aza-dC to investigate the cause of the decreased expression of WIF-1 in the GBC-SD cell line. The GBC-SD cells were cultured in DMEM containing $10 \%$ fetal bovine serum. The 5 -Aza-dC was added to the culture solution at a final drug concentration of $1 \mu \mathrm{g} / \mathrm{ml}$. The drug-containing medium was replaced every $24 \mathrm{~h}$. After 5 days, the cells were collected for experiments. GBC-SD cells cultured in DMEM without the presence of drugs were used as controls. The PCR conditions were the same as those described above.

Plasmids and stable transfection procedure. A vector containing WIF-1 and an empty vector (GV141) were purchased from Shanghai Genechem Co., Ltd. (Shanghai, China). Lipofectamine 2000 (Invitrogen; Thermo Fisher Scientific, Inc.) was used as the transfection reagent. The GBC-SD cells were diluted to 1,000 cells $/ \mathrm{ml}$ and incubated at $37^{\circ} \mathrm{C}$ and $5 \% \mathrm{CO}_{2}$ in 24-well plates. G418 (Invitrogen; Thermo Fisher Scientific, Inc.) was used for selection. Following 1 week of G418 selection, cell line stably expressing WIF-1 (WGBC-SD) and expressing the empty plasmid (NGBC-SD) were produced, and these cells were expanded for further experiments.

Detection of the proliferation ability of $G B C-S D, W G B C-S D$ and NGBC-SD cells. Cell Counting Kit-8 (CCK 8) kits, purchased from Beyotime Institute of Biotechnology were used to detect the proliferation of the GBC-SD, WGBC and NGBC cells. The three types of tumor cells in the logarithmic growth phase were digested with $0.25 \%$ trypsin and counted using a cell counting chamber (Shanghai Baili Science and Technology Co., Ltd., Shanghai, China). Subsequently, $1.5 \times 10^{3}$ cells per well were seeded into 96-well plates, with three wells for each group. The cells were cultured under saturated humidity conditions at $37^{\circ} \mathrm{C}$ and $5 \% \mathrm{CO}_{2}$. Following culture for 24, 48, 72, 96 and $120 \mathrm{~h}$, the culture media were replaced with $100 \mu \mathrm{l}$ fresh culture media with CCK-8 (90 $\mu \mathrm{l}$ culture medium $+10 \mu \mathrm{l}$ CCK-8). The plates were incubated for $2 \mathrm{~h}$ and the absorbance was measured at $450 \mathrm{~nm}$ using a standard instrument (JS-2010; Shanghai Peiqing Science and Technology Co., Ltd.). On the final day, the data were analyzed using SPSS 13.0 (SPSS, Inc., Chicago, IL, USA).

Assessment of the invasion and metastatic abilities of $G B C-S D$, $W G B C-S D$ and NGBC-SD cells. Transwell plates were purchased from Corning (Corning, NY, USA). A total of $10 \mathrm{ml}$ frozen fibronectin (FN; Becton Dickinson; BD Biosciences,
San Diego, CA, USA) was applied to the upper chamber of the Transwell plates, and biological Matrigel (Becton Dickinson; BD Biosciences) was applied to the lower chamber. Subsequently, $2 \times 10^{5}$ of the GBC-SD, WGBC and NGBC cells were suspended in $200 \mu \mathrm{l}$ serum-free DMEM, the suspension was added to the upper well. A total of $0.8 \mathrm{ml}$ DMEM with $10 \%$ fetal bovine serum was added to the lower well. The samples were incubated for $30 \mathrm{~h}$ at $37^{\circ} \mathrm{C}$ and $5 \% \mathrm{CO}_{2}$. The quantification procedure was as follows: Absorbing of the supernatant; washing once with phosphate-buffered saline (PBS), fixing with 95\% ethanol and $5 \%$ acetic acid for $30 \mathrm{~min}$, gently wiping the upper chamber, washing with PBS and staining with hematoxylin. The average values from five visual fields (magnification, $x 400$ ) were calculated.

For the migration analysis, the methods of seeding and cultivation were the same as those described above, with the exception that $10 \mu \mathrm{l} \mathrm{FN}$ was applied to the upper well. The cultivation was terminated following $8 \mathrm{~h}$ in the incubator at $37^{\circ} \mathrm{C}$ and $5 \% \mathrm{CO}_{2}$. The methods for fixing, staining and microscopy were the same as those described above.

The degradation of the extracellular matrix of tumors is an important process during tumor invasion and metastasis, and this degradation can be accomplished by the secretion of matrix metalloproteinases (MMPs). The secretion of MMPs increases tumor invasive and metastatic abilities. The present study investigated the activities of MMP-2 and MMP-9 in the three cell groups using the kits from Beyotime Institute of Biotechnology.

Apoptosis of GBC-SD, WGBC-SD and NGBC-SD cells. Annexin V-fluorescein isothiocyanate (FITC)/propidium iodide (PI) double staining was used to detect the apoptotic rates of the three groups of cells. The Annexin V-FITC/PI kit was purchased from Nanjing KeyGen Biotech Co., Ltd. (Nanjing, China). Cells $\left(10^{6}\right)$ cells in the logarithmic growth were collected for the analysis of apoptosis, which was performed according to the kit instructions. The apoptotic rates were measured using a flow cytometer (Bio-Rad Laboratories, Inc., Hercules, CA, USA). A compensation adjustment of fluorescence was performed prior to the assessment.

Detection of the oncogenicity of $G B C-S D, W G B C-S D$ and $N G B C-S D$ in vivo. Specific-Pathogen-Free nude mice were used in the pilot study, and a total of $15 \mathrm{BALB} / \mathrm{C}$ (nu/nu) were used in the current study (4-6 weeks old; 16-20 grams 12/12 h light/dark cycle; $45-50 \%$ humidity; $25-27^{\circ} \mathrm{C}$; Shanghai Laboratory Animal Center, Chinese Academy of Sciences (Shanghai, China. The mice were caged separately with access to sterilized food and water and were randomly divided into three groups, each containing five mice. The GBC-SD, WGBC-SD and NGBC-SD cell lines were inoculated into the left axilla of the mouse forelimb. The number of injected tumor cells for each mouse was $10^{7}$ cells. The mice were sacrificed by cervical dislocation 5 weeks later. The tumors were resected completely and weighed, followed by sectioning.

Protein expression in $G B C-S D, W G B C-S D$ and $N G B C-S D$ cells. An AAH CYT-G10-4 protein chip kit, purchased from RayBiotech Company (Norcross, GA, USA) was used to detect changes in protein expression in the three groups of cells. The 


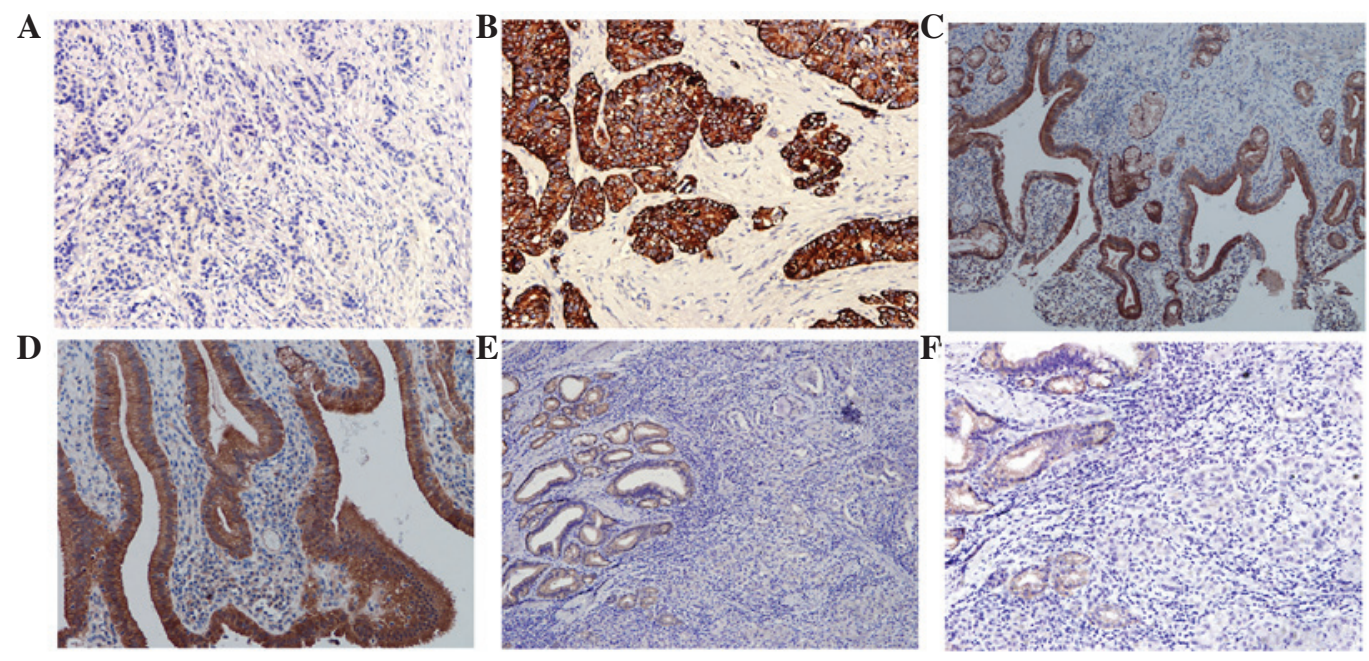

Figure 1. (A) Expression of WIF-1 was absent in the majority of gallbladder cancer cases. (B) In the positive gallbladder cancer cases, the expression of WIF-1 was typically weak. This image represents the only strong-positive case in the 40 cases. (C and D) Expression of WIF-1 was positive in all cholecystitis cases. Images were captured at magnification, x100 and x200. (E and F) In the crash area of the tumor and normal tissue, the expression of WIF-1 differed markedly. The expression of WIF-1 was positive in the left area of the normal mucosa, but negative in the right area containing the tumor. WIF-1, Wnt inhibitory factor 1.

cells $\left(>10^{6}\right)$ were collected following lysis and were adjusted to the same concentration. The AAH CYT-G10-4 protein chip kit was used, according to the kit instructions. When all steps were completed, a laser scanner was used to detect the fluorescent signal, and the data were analyzed

Statistical analysis. All data were analyzed using SPSS software, version 13.0 (SPSS, Inc., Chicago, IL, USA). The data were analyzed using the $\chi^{2}$ test. $\mathrm{P}<0.05$ was considered to indicate a statistically significant difference.

\section{Results}

WIF-1 shows reduced expression in gallbladder cancer and tumor cell lines. In the 40 clinical cases of gallbladder cancer, only 15 cases were positive for WIF-1, with a rate of $25 \%$ (15/40). In the 50 cases of cholecystitis, WIF-1 was expressed in $100 \%$ of the samples (50/50; Fig. 1). The difference between the two groups was significant $(\mathrm{P}<0.001)$. In the GBC-SD, NOZ and SGC-996 tumor cell lines, the expression levels of WIF-1 were similar to the clinical examples, in that neither mRNA or protein were detected (Fig. 2A and B).

Loss of the expression of WIF-1 is associated with promoter methylation and is rescued by 5-Aza- $d C$. The initial experiment showed that, in the three tumor cell lines, the mRNA expression of WIF-1 was absent. Using methylation-specific PCR, it was found that this absence was associated with gene promoter methylation, which revealed methylated bands and no unmethylated bands. These data showed that promoter methylation was high in the gallbladder cancer cell lines (Fig. 2C). Following treatment with 5-Aza-dC, the mRNA expression of WIF-1 in the tumor cells recovered (Fig. 2D). These results suggested that promoter methylation led to the absence of the mRNA expression of WIF-1.

WIF-1 suppresses the proliferation, invasion and metastasis of GBC-SD cells and increases the apoptosis of the GBC-SD cells. In the present study, a GBC-SD cell line stably expressing WIF-1 (WGBC-SD) and a control cell line containing an empty plasmid, (NGBC-SD) were constructed. Although 5-Aza-dC restored the expression of WIF-1, it also affected other gene promoters including p16, human mutL homolog 1 and runt-related transcription factor 3 . Therefore, it was necessary to construct a stable cell line expressing WIF-1. Following transfection and selection with G418, a confirmation experiment was performed (Fig. 2E). For this, the GBC-SD tumor cell line was selected as the transfection target due to its convenient morphological characteristics.

Based on previous experiments, the present study examined the effect of the expression of WIF-1 on proliferation, invasion, metastasis and apoptosis. As an important inhibitor of the Wnt pathway, recovery of WIF-1 was expected to affect tumor cell behavior. The results showed that WIF-1 had a marked suppressive effect on the tumor cells and increased apoptosis (Fig. 3).

WIF-1 regulates protein expression. To explain the inhibited tumor cell invasion and metastasis, the present study measured the expression levels of MMP-2 and MMP-9 in the GBC-SD, NGBC-SD and WGBC-SD cells. MMP-2 and MMP-9 degrade the extracellular matrix and thus are involved in the spread of cancer. The expression levels of MMP-2 and MMP-9 were significantly lower in the WGBC-SD cells (Fig. 4A), compared with those in the GBC-SD and NGBC-SD cells $(\mathrm{P}<0.001)$.

$\beta$-catenin is key in Wnt signaling, and controls cellular proliferation, invasion and apoptosis. The present study performed western blot analysis to analyze the expression of $\beta$-catenin in the three cell lines. The expression of $\beta$-catenin was downregulated in the WGBC-SD cells, compared with the GBC-SD and NGBC-SD cells $(\mathrm{P}<0.001)$. No difference in expression levels were observed between the GBC-SD and NGBC-SD cells ( $\mathrm{P}>0.05$; Fig. 4B).

The present study subsequently detected the expression of proteins using a protein chip to identify novel proteins, which may be possible WIF-1 targets, including proteins involved in cell motility and tumor angiogenesis. Compared with the NGBC-SD 
A

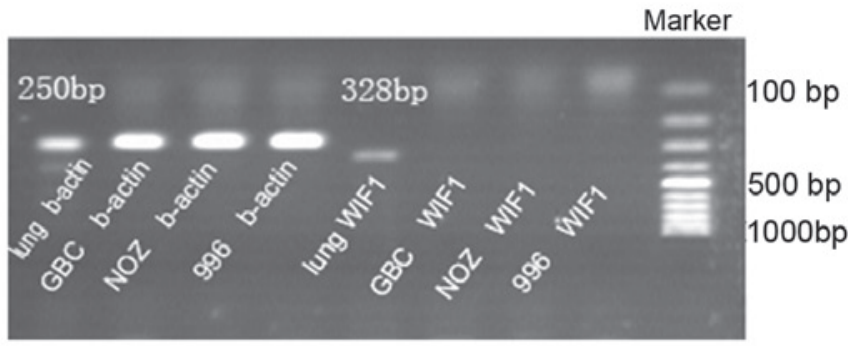

C
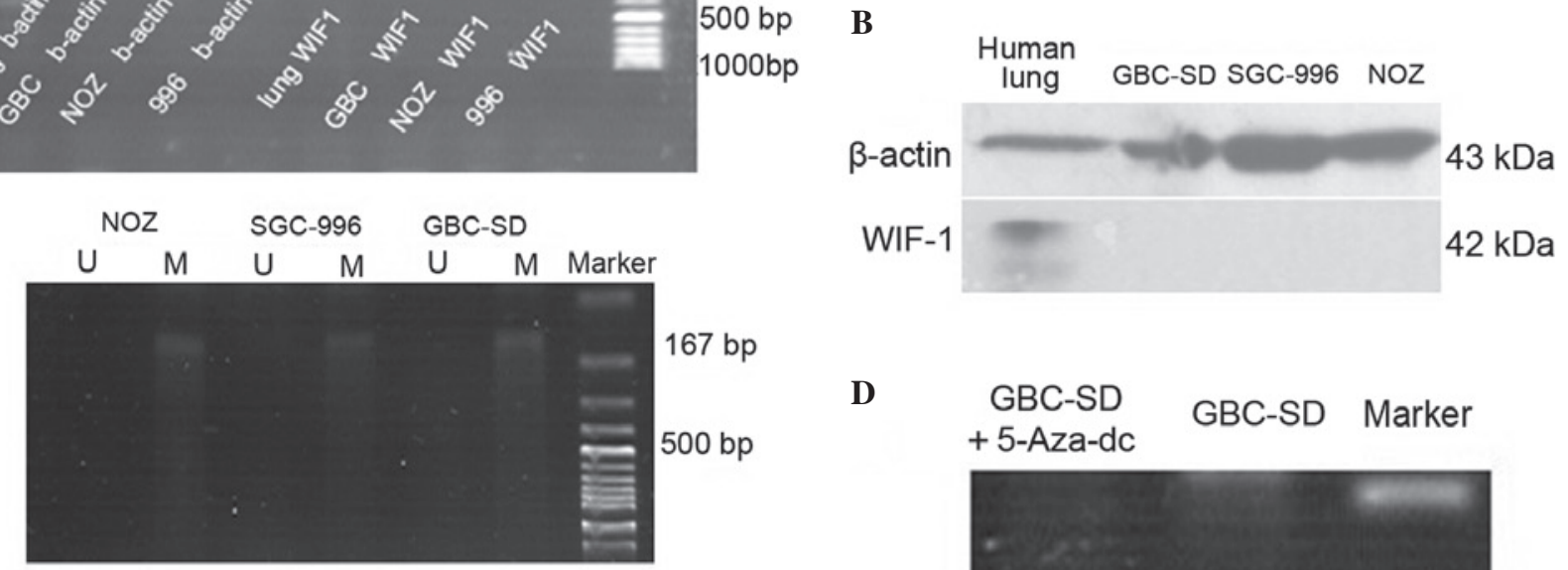

$\mathbf{E}$

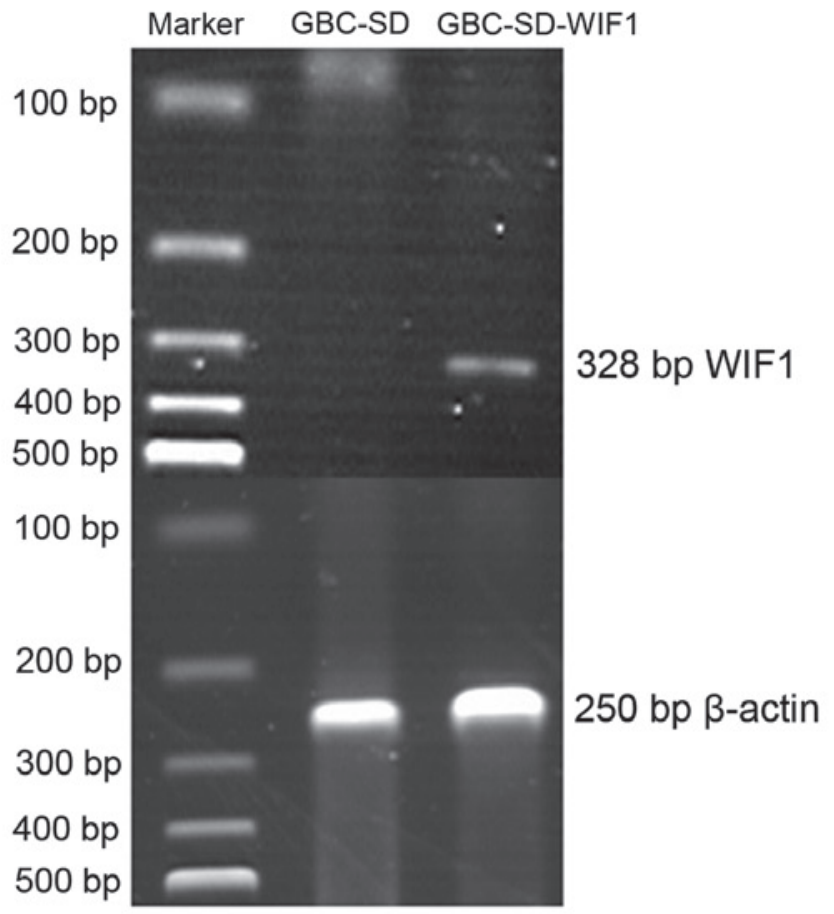

D

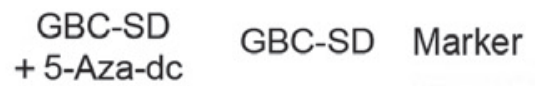

$328 \mathrm{bp}$

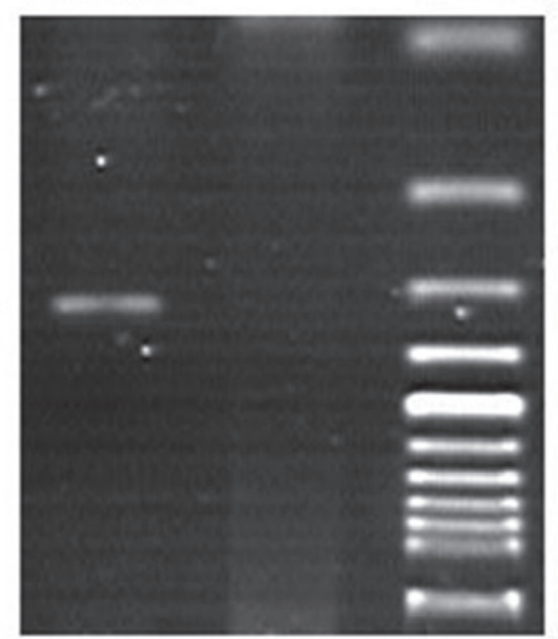

Figure 2. (A and B) RT-PCR and western blot analyses of the three tumor cell lines showed that the mRNA and protein expression of WIF-1 were negative, similar to the clinical specimens. Human lung tissue was used as a control. (C) Promoter methylation in the three cell lines. Only methylated bands were observed. (D) Recovery of the expression of WIF-1 following treatment of GBC-SD cells with 5-Aza-dC. (E) Expression of WIF-1 was examined using RT-PCR analysis in the WGBC-SD cells. The transfection was successful and stable. WIF-1, Wnt inhibitory factor 1; 5-Aza-dC, 5-aza-2-deoxycytidine; RT-PCR, reverse transctipyion-polymerase chain reaction; $\mathrm{U}$, unmethylated; $\mathrm{M}$, methylated.

cells, the expression levels of DKK-4, DPPIV, E-cadherin and certain other proteins were increased in the WGBC-SD cells, and the expression levels of other proteins, including CA199, CA125 and angiostatin were decreased (Fig. 4C). This was the first time, to the best of out knowledge that these changes have been reported in gallbladder cancer. It was concluded that these changes were associated with the behavior of GBC-SD, NGBC-SD and WGBC-SD cells.

WIF-1 inhibits the oncogenicity of GBC-SD cells in vivo. In the in vivo experiments, 15 nude mice were successfully inoculated, and the tumors were excised from the mice in the different groups and were then weighed. No lymph node metastases were observed in the three groups of nude mice. There was a significant difference in tumor weight between the WGBC-SD group and the GBC-SD group, and between the WGBC-SD group and the NGBC-SD group $(\mathrm{P}<0.001)$. No significant difference in tumor weight was observed between the GBC-SD group and the NGBC-SD group $(\mathrm{P}>0.05)$. The results indicated that WIF-1 inhibited the oncogenicity of the GBC-SD cells in vivo and in vitro (Fig. 4D). 

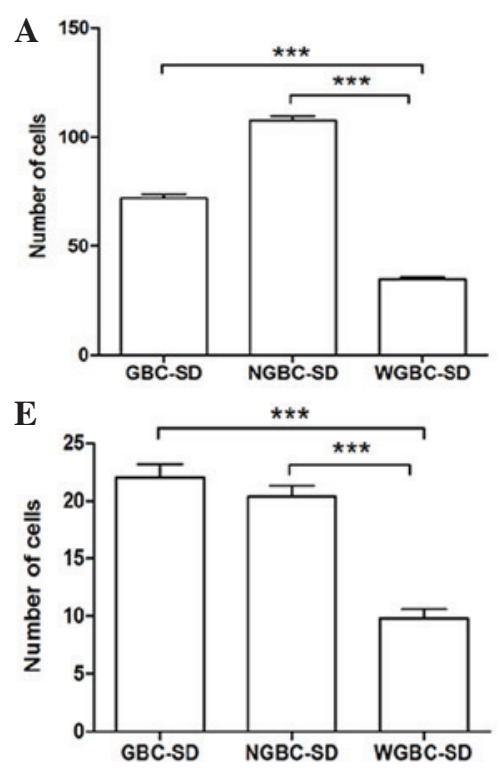

B

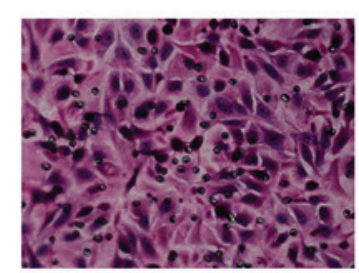

F

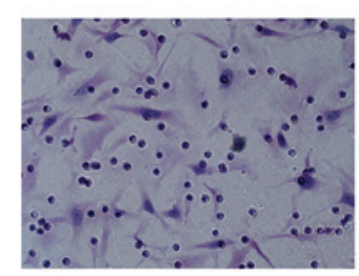

C

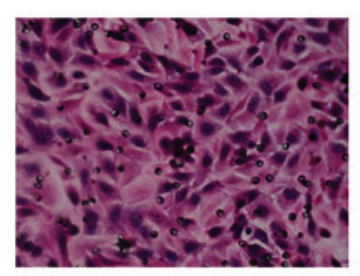

G

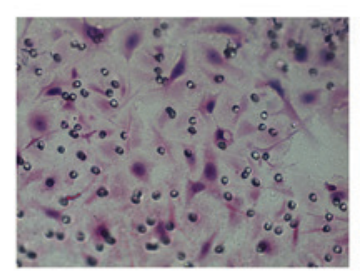

D

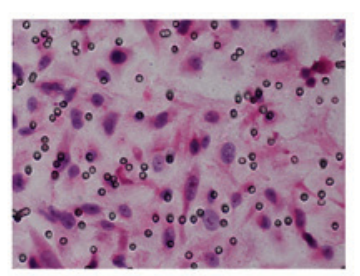

H

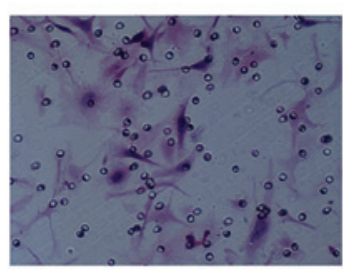

I

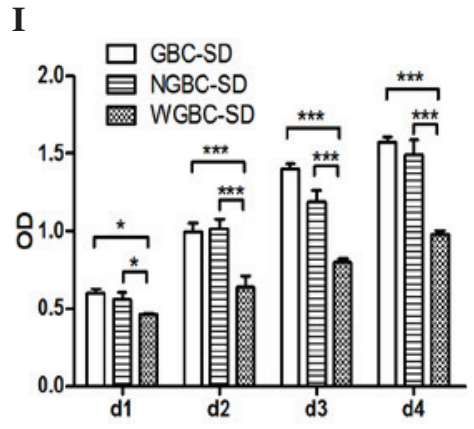

J

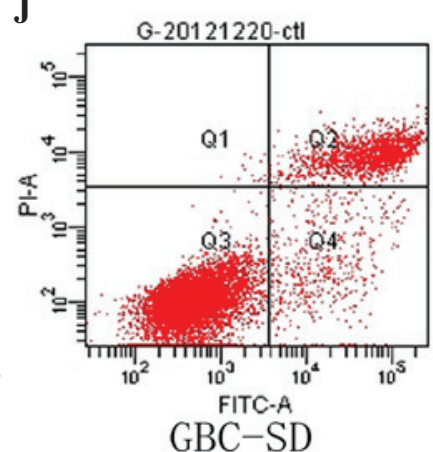

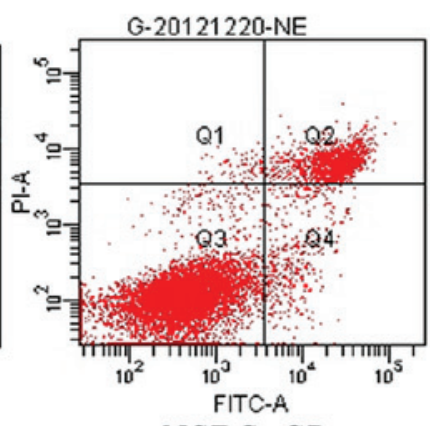

NGBC-SD

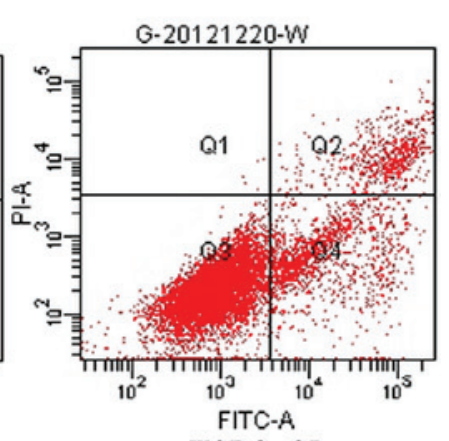

WGBC-SD

K

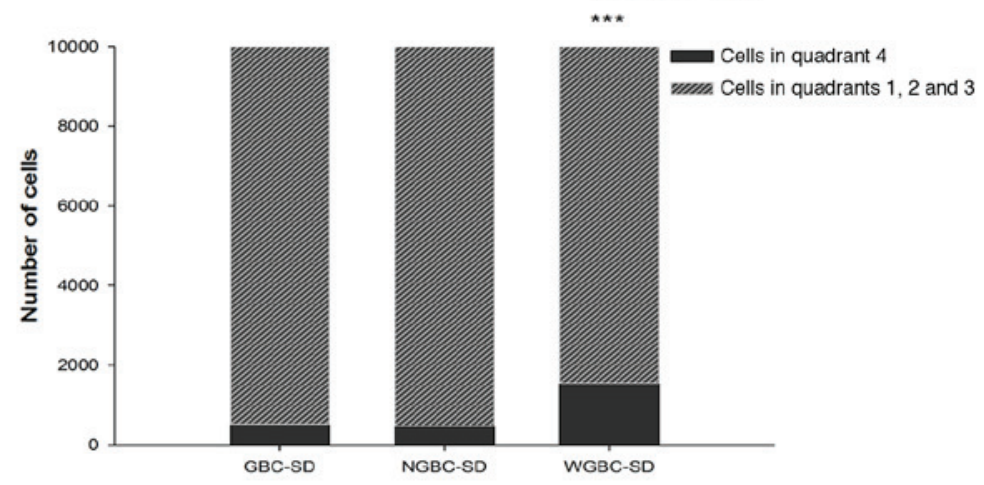

Figure 3. (A) Significant differences were observed in the invasive ability of the (B) GBC-SD, (C) NGBC-SD and (D) WGBC-SD cells (magnification, $x 400$ ). (E) In an experiment measuring the metastatic ability of (F) GBC-SD, (G) NGBC-SD and (H) WGBC-SD cells, the results corresponded to those of the invasion experiment.(I) GBC-SD, NGBC-SD and WGBC-SD cells exhibited different proliferation rates. (J and K) Flow cytometry was used to detect apoptosis. The cells in quadrant $(\mathrm{Q}) 4$ were counted as apoptotic cells. The rate of apoptosis in the WGBC-SD cells was significantly higher, compared with the rates in the GBC-SD and NGBC-SD cells $(\mathrm{P}<0.001)$. No significant difference in the apoptotic rate was found between the GBC-SD and NGBC-SD cells $(\mathrm{P}>0.05)$. ${ }^{*} \mathrm{P}<0.05$ and ${ }^{* * * *} \mathrm{P}<0.001$. WGBC-SD, GBC-SD cells stably expressing WIF-1; NGBC-SD, empty vector-transfected GBC-SD cells; OD, optical density; FITC, fluorescein isothiocyanate; PI, propidium iodide.

\section{Discussion}

In vivo, the Wnt pathway controls cell proliferation and differentiation, and abnormal activation often leads to tumor development (18). The inhibition of this abnormally activated signaling pathway is an area of interest. The expression of WIF-1, a potent Wnt signaling pathway inhibitor, is low in a several types of tumor. The present study showed that, in gallbladder cancer, the expression of WIF-1 was significantly decreased. WIF-1 was positive in only 10 cases $(25 \%$ of the cases). In 50 cases of chronic cholecystitis, the expression rate of WIF-1 was $100 \%$. This result suggested that, in the development of gallbladder cancer, WIF-1 inactivation may occur early in the process. The inactivation is likely to be the same as that in gastrointestinal tumors (19), which occurs due to abnormal methylation of the WIF-1 gene promoter. The inactivation of WIF-1 activates the Wnt pathway, which then leads to abnormal cellular proliferation and eventual tumor formation. 
A
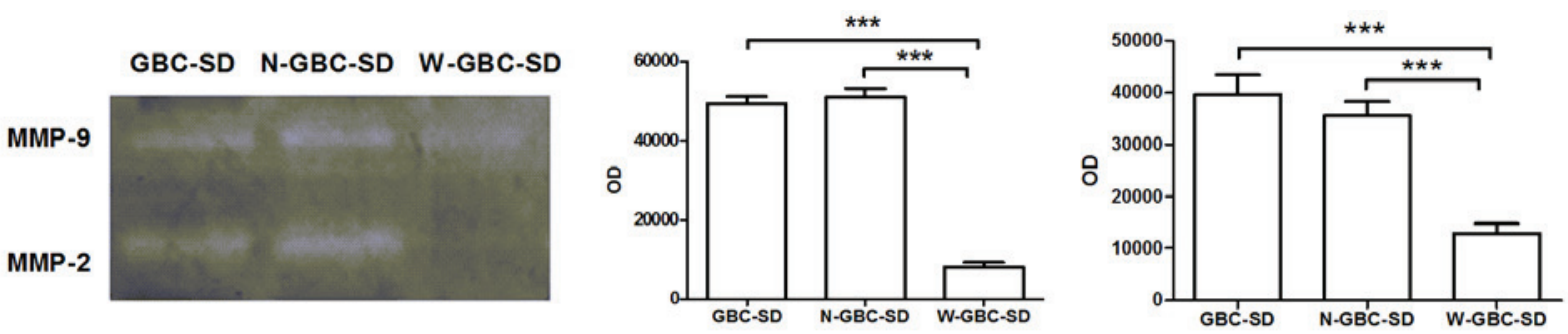

B

GBC-SD N-GBC-SD W-GBC-SD

$\beta$-catenin

$\beta$-actin
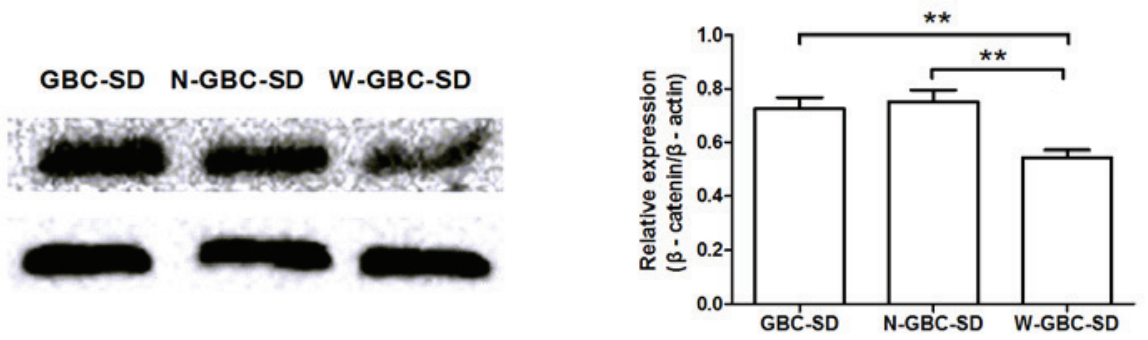

C

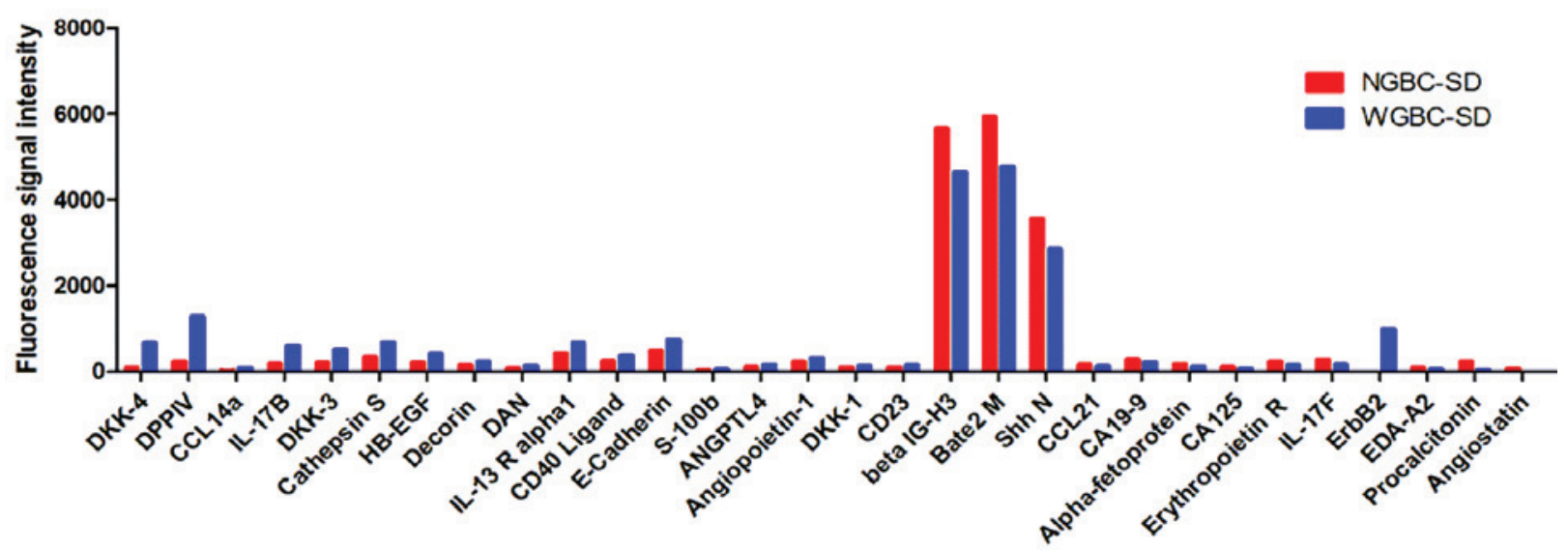

D

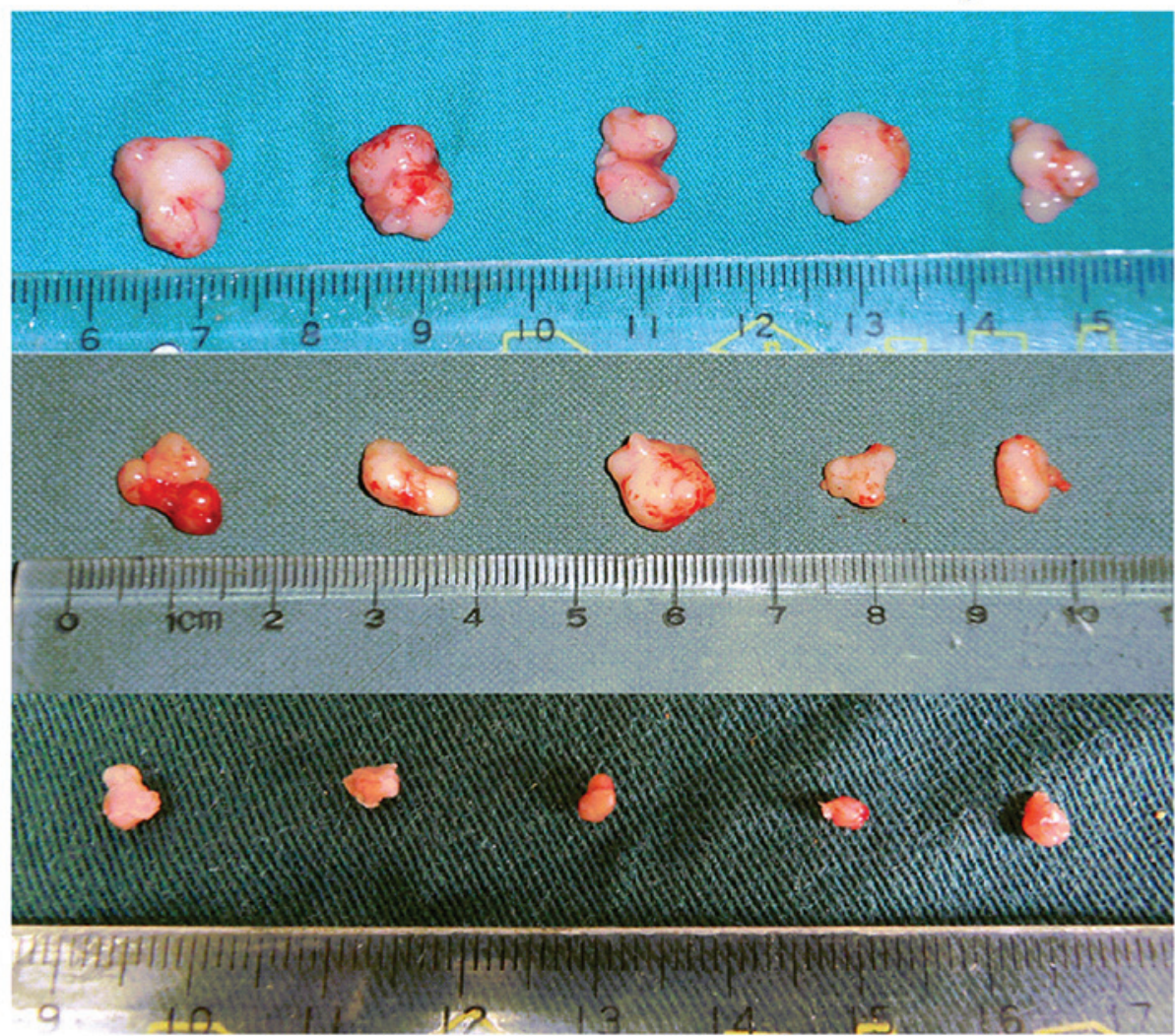

GBC-SD

N-GBC-SD

W-GBC-SD

Figure 4. (A) Expression levels of MMP-2 and MMP-9 were significantly lower in the WGBC-SD cells, compared with the GBC-CD and NGBC-SD groups $(\mathrm{P}<0.001)$. (B) Expression of $\beta$-catenin was detected using western blot analysis. The expression of $\beta$-catenin was lower in the WGBD-SD cells, compared with the GBC-CD and NGBC-SD groups $(\mathrm{P}<0.01)$. (C) Proteins extracted from the NGBC-SD and WGBC-SD cells were analyzed using a protein chip assay. (D) Differences in oncogenicity between GBC-SD, NGBC-SD and WGBC-SD cells. ${ }^{* *} \mathrm{P}<0.01$ and ${ }^{* * * *} \mathrm{P}<0.001$. MMP, matrix metalloproteinase; WGBC-SD, GBC-SD cells stably expressing Wnt inhibitory factor 1; NGBC-SD, empty vector-transfected GBC-SD cells. 
In the present study, WIF-1 was not expressed in the GBC-SD, SGC-996 or NOZ cell lines, as determined using PCR and western blot analyses. A GBC-SD cell line stably expressing WIF-1 was constructed for further investigation, as well as a negative control.

Following a study in 1997 by Schroeder et al (20), which reported that $\mathrm{CPG}$ island methylation of the P53 tumor suppressor gene affects its transcriptional activity, numerous studies have shown that gene promoter hypermethylation is an important factor in gene expression (21-28). The methylation of tumor suppressor gene promoters often leads to the inactivation of tumor suppressor genes and tumorigenesis (22). The present study performed WIF-1 gene promoter methylation analysis in the three gallbladder cancer cell lines. The results showed that, similar to other types of tumor (23-26), the WIF-1 gene promotor in the gallbladder cancer cell lines was completely methylated. This methylation likely caused the lack of WIF-1 expressed in the tumor cell lines. Detecting the promoter methylation of genes in tumors is significant, and this technology has been used in the diagnosis of lung cancer $(27,28)$. Promoter methylation of the WIF-1 gene in the diagnosis of gallbladder cancer has not been reported previously, and further investigation is required prior to the clinical application of such diagnostic assessment.

To confirm that the lack in the expression of WIF-1 was caused by promoter methylation, the present study treated the GBC-SD cells with 5-Aza-dC, a potent demethylating drug. As an inhibitor of gene promoter methylation, 5-Aza-dC binds to DNA methylation enzymes and inhibits their activity. The results of the present study confirmed that, following treatment, the mRNA expression of WIF-1 was recovered. Thus, in the GBC-SD cells, the absence of the expression of WIF-1 was associated with promoter methylation. 5-Aza-dC has been used in leukemia (29), melanoma and renal cell carcinoma as an adjuvant drug (30), however, its use in gallbladder cancer has not been reported. Future investigations may determine whether 5-Aza-dC can improve the prognosis of patients with gallbladder cancer.

The inhibition of WIF-1 in tumor cells has been confirmed in a series of previous studies (31-33). The investigation of the biological behavior of gallbladder cancer cell lines in the present study also showed that WIF-1 slowed down cell replication and inhibited tumor cell proliferation. As a particularly invasive type of cancer, invasion is an important factor leading to gallbladder cancer-associated mortality (34). In the present study, a plasmid expressing WIF-1 was transfected into GBC-SD cells, and it was found that the ability of the cells to invade and metastasize decreased significantly. The results for MMP were similar. MMP-2 and MMP-9 are involved, not only in physiological processes, including tissue repair, but are also involved in degradation of the extracellular matrix, which promotes tumor invasion and metastasis (35). The experimental results in the present study showed that WIF-1 reduced the secretion of these two enzymes. This result may explain why WIF-1 reduced the invasion and metastasis of gallbladder cancer. Taken together, these results indicated that WIF-1 markedly suppressed gallbladder cancer.

To validate the inhibitory effects noted in the tumor cell lines, the present study also performed animal experiments. The tumorigenicity of the transfected GBC-SD cells was significantly lower, compared with the other two groups of cells. The average weight of the tumors was only $1 / 10$ of the weight of those in the control groups.

As a widely influential factor, which inhibits the Wnt/ $\beta$-catenin signaling pathway, the expression of WIF-1 in the tumor inevitably leads to changes in a series of downstream genes. In the present study, downregulation of $\beta$-catenin at the protein level was observed in the WGBC-SD cells, with downregulation of pathway activity. Protein chip technology was also used to identify the expression of proteins, which are important in the physiological and pathological course of gallbladder cancer. Protein chips are a relatively novel type of high-throughput detection technology, which can rapidly detect protein expression $(36,37)$. The results showed alterations in the expression levels of a number of proteins involved in cell cycle and apoptosis. The expression levels of Cripto-1, DKK-4, CCL14a, DPPIV, Cathepsin S, EpCAM, E-Cadherin, IL-17B, DKK-3, Decorin, IL-17C, CA19-9, HB-EGF, IL-13 R alpha1, EG-VEGF, CA125, CEACAM-1, HVEM and PSA-free increased, and the expression levels of EDA-A2, Carbonic Anhydrase IX, Angiostatin, and Procalcitonin decreased. This may have led to the changes in tumor behavior.

As an important signaling molecule in the Wnt signaling pathway, WIF-1 can effectively inhibit this signaling pathway, however, it is not the only inhibitor (38-40). Investigating the mechanism of signal inhibiting factors in the Wnt signaling pathway may assist in prolonging survival rates and improving patient quality of life. As Wnt signal transduction is complex and affects a wide range of other metabolic pathways, further investigation of its mechanisms is warranted to improve therapeutic efficacy in the treatment of gallbladder cancer.

In conclusion, the present study demonstrated that the expression levels of WIF-1 were low in gallbladder cancer tumor tissues and the GBC-SD, SGC-996 and NOZ gallbladder cancer cell lines. This low expression was associated with the methylation status of the WIF-1 gene promotor. Following treatment of the GBC-SD cell line with the demethylation agent, 5-Aza-dC, the expression of WIF-1 recovered. Following establishment of cell lines stably expressing WIF-1, it was found that the proliferation, invasion, metastasis and tumorigenicity of the established cell lines were significantly decreased, and the apoptotic rates were increased. Protein expression levels were also altered in the modified cells. These results suggest that WIF-1 may be an effective treatment target for gallbladder cancer.

\section{Acknowledgements}

This study was supported by the National Natural Science Foundation of China (grant no. 81272373).

\section{References}

1. Donohue JH, Stewart AK and Menck HR: The national cancer data base report on carcinoma of the gallbladder, 1989-1995. Cancer 83: 2618-2628, 1998.

2. Coburn NG, Cleary SP, Tan JC and Law CH: Surgery for gallbladder cancer: A population-based analysis. J Am Coll Surg 207: 371-382, 2008.

3. Zhu AX, Hong TS, Hezel AF and Kooby DA: Current management of gallbladder carcinoma. Oncologist 15: 168-181, 2010. 
4. Nusse R and Varmus HE: Many tumors induced by the mouse mammary tumor virus contain a provirus integrated in the same region of the host genome. Cell 31: 99-109, 1982.

5. Wodarz A and Nusse R: Mechanisms of Wnt signaling in development. Annu Rev Cell Dev Biol 14: 59-88, 1998.

6. Clevers $\mathrm{H}$ : Wnt/beta-catenin signaling in development and disease. Cell 127: 469-480, 2006.

7. Taketo MM: Wnt signaling and gastrointestinal tumorigenesis in mouse models. Oncogene 25: 7522-7530, 2006.

8. Van Scoyk M, Randall J, Sergew A, Williams LM, Tennis M and Winn RA: Wnt signaling pathway and lung disease. Trans Res 151: 175-180, 2008.

9. Karamboulas C and Ailles L: Developmental signaling pathways in cancer stem cells of solid tumors. Biochim Biophys Acta 1830: 2481-2495, 2013

10. Hsieh JC, Kodjabachian L, Rebbert ML, Rattner A, Smallwood PM, Samos CH, Nusse R, Dawid IB and Nathans J: A new secreted protein that binds to Wnt proteins and inhibits their activities. Nature 398: 431-436, 1999.

11. Liepinsh E, Bányai L, Patthy L and Otting G: NMR structure of the WIF domain of the human Wnt-inhibitory factor-1. J Mol Biol 357: 942-950, 2006.

12. Kawano Y and Kypta R: Secreted antagonists of the Wnt signaling pathway. J Cell Sci 116: 2627-2634, 2003.

13. Kim AS, Lowenstein DH and Pleasure SJ: Wnt receptors and Wnt inhibitors are expressed in gradients in the developing telencephalon. Mech Dev 103: 167-172, 2001.

14. Wissmann C, Wild PJ, Kaiser S, Roepcke S, Stoehr R, Woenckhaus M, Kristiansen G, Hsieh JC, Hofstaedter F, Hartmann A, et al: WIF1, a component of the Wnt pathway, is down-regulated in prostate, breast, lung and bladder cancer. J Pathol 201: 204-212, 2003.

15. Licchesi JD, Westra WH, Hooker CM, Machida EO, Baylin SB and Herman JG: Epigenetic alteration of Wnt pathway antagonists in progressive glandular neoplasia of the lung. Carcinogenesis 29 : 895-904, 2008.

16. Byun T, Karimi M, Marsh JL, Milovanovic T, Lin F and Holcombe RF: Expression of secreted Wnt antagonists in gastrointestinal tissues: Potential role in stem cell homeostasis. J Clin Pathol 58: 515-519, 2005.

17. Frommer M, McDonald LE, Millar DS, Collis CM, Watt F, Grigg GW, Molloy PL and Paul CL: A genomic sequencing protocol that yields a positive display of 5-methylcytosine residues in individual DNA strands. Proc Natl Acad Sci USA 89: 1827-1831, 1992.

18. Behrens $\mathrm{J}$ and Lustig B: The Wnt connection to tumorigenesis. Int J Dev Biol 48: 477-487, 2004.

19. Taniguchi $\mathrm{H}$, Yamamoto $\mathrm{H}$, Hirata T, Miyamoto N, Oki M, Nosho K, Adachi Y, Endo T, Imai K and Shinomura Y: Frequent epigenetic inactivation of Wnt inhibitory factor-1 in human gastrointestinal cancers. Oncogene 24: 7946-7952, 2005.

20. Schroeder M and Mass MJ: CpG methylation inactivates the transcriptional activity of the promoter of the human p53 tumor suppressor gene. Biochem Biophys Res Commun 235: 403-406, 1997.

21. Holmes R and Soloway PD: Regulation of imprinted DNA methylation. Cytogenet Genome Res 113: 122-129, 2006.

22. Das PM and Singal R: DNA methylation and cancer. J Clin Oncol 22: 4632-4642, 2004.

23. Batra S, Shi Y, Kuchenbecker KM, He B, Reguart N, Mikami I, You L, Xu Z, Lin YC, Clément G and Jablons DM: Wnt inhibitory factor-1, a Wnt antagonist, is silenced by promoter hypermethylation in malignant pleural mesothelioma. Biochem Biophys Res Commun 342: 1228-1232, 2006.
24. Wang Y, Zhu CS, Bi KH, Xu WW, Dong L and Hou M: Study of WIF-1 promoter methylation with expressions of $\beta$-catenin in acute leukemia. Zhonghua Yi Xue Za Zhi 91: 2858-2860, 2011 (In Chinese).

25. Alvarez C, Tapia T, Cornejo V, Fernandez W, Muñoz A, Camus M, Alvarez M, Devoto L and Carvallo P: Silencing of tumor suppressor genes RASSF1A, SLIT2 and WIF1 by promoter hypermethylation in hereditary breast cancer. Mol Carcinog 52: 475-487, 2013.

26. Chan SL, Cui Y, van Hasselt A, Li H, Srivastava G, Jin H, Ng KM, Wang Y, Lee KY, Tsao GS, et al: The tumor suppressor Wnt inhibitory factor 1 is frequently methylated in nasopharyngeal and esophageal carcinomas. Lab Invest 87: 644-650, 2007.

27. Palmisano WA, Divine KK, Saccomanno G, Gilliland FD, Baylin SB, Herman JG and Belinsky SA: Predicting lung cancer by detecting aberrant promoter methylation in sputum. Cancer Res 60: 5954-5958, 2000

28. Belinsky SA, Nikula KJ, Palmisano WA, Michels R, Saccomanno G, Gabrielson E, Baylin SB and Herman JG: Aberrant methylation of p16 (INK4a) is an early event in lung cancer and a potential biomarker for early diagnosis. Proc Natl Acad Sci USA 95: 11891-11896, 1998.

29. Bryan J, Kantarjian H, Garcia-Manero G and Jabbour E: Pharmacokinetic evaluation of decitabine for the treatment of leukemia. Expert Opin Drug Metab Toxicol 7: 661-672, 2011

30. Gollob JA, Sciambi CJ, Peterson BL, Richmond T, Thoreson M, Moran K, Dressman HK, Jelinek J and Issa JP: Phase I trial of sequential low-dose 5-aza-2'-deoxycytidine plus high-dose intravenous bolus interleukin-2 in patients with melanoma or renal cell carcinoma. Clin Cancer Res 12: 4619-4627, 2006.

31. Kawakami K, Hirata H, Yamamura S, Kikuno N, Saini S, Majid S, Tanaka Y, Kawamoto K, Enokida H, Nakagawa M and Dahiya R: Functional significance of Wnt inhibitory factor-1 gene in kidney cancer. Cancer Res 69: 8603-8610, 2009.

32. Rubin EM, Guo Y, Tu K, Xie J, Zi X and Hoang BH: Wnt inhibitory factor 1 decreases tumorigenesis and metastasis in osteosarcoma. Mol Cancer Ther 9: 731-741, 2010.

33. Wu J, Fang J, Yang Z, Chen F, Liu J and Wang Y: Wnt inhibitory factor-1 regulates glioblastoma cell cycle and proliferation. J Clin Neurosci 19: 1428-1432, 2012.

34. Kaushik SP: Current perspectives in gallbladder carcinoma. J Gastroenterol Hepatol 16: 848-854, 2001.

35. Benaud C, Dickson RB and Thompson EW: Roles of the matrix metalloproteinases in mammary gland development and cancer. Breast Cancer Res Treat 50: 97-116, 1998

36. Kim HB, Kim CK, Ijima K, Kobayashi T and Kita H: Protein microarray analysis in patients with asthma: Elevation of the chemokine PARC/CCL18 in sputum. Chest 135: 295-302, 2009.

37. Wu DJ, Qian MJ, Rong RM, Xu M and Zhu TY: Expression of inflammation cytokines and network analysis in acute rejection of renal transplantation. Zhonghua Yi Xue Za Zhi 92: 2976-2979, 2012 (In Chinese)

38. Enomoto-Iwamoto M, Kitagaki J, Koyama E, Tamamura Y, Wu C, Kanatani N, Koike T, Okada H, Komori T, Yoneda T, et al: The Wnt antagonist Frzb-1 regulates chondrocyte maturation and long bone development during limb skeletogenesis. Dev Biol 251: 142-156, 2002

39. Dun Y, Yang Y, Xiong Z, Feng M, Zhang Y, Wang M, Xiang J, $\mathrm{Li} \mathrm{G}$ and Ma R: Induction of Dickkopf-1 contributes to the neurotoxicity of MPP (+) in PC12 cells via inhibition of the canonical Wnt signaling pathway. Neuropharmacology 67: 168-175, 2013.

40. Chen B, Ma X, Liu S, Zhao W and Wu J: Inhibition of lung cancer cells growth, motility and induction of apoptosis by Klotho, a novel secreted Wnt antagonist, in a dose-dependent manner. Cancer Biol Ther 13: 1221-1228, 2012. 